\title{
Brazilian Scale of Hearing and Language Development: Normality Curve for Infants and Children from 0 to 24 Months Old with Normal Hearing
}

\author{
Claudia Moretti ${ }^{1}$ Angela Ribas ${ }^{2}$ Ana Cristina Guarinello ${ }^{3}$ Marine Rosa ${ }^{4}$ Renato Riesemberg ${ }^{5}$ \\ Trissia Vassoler $^{2}$ Giselle Sypczuk $^{6}$ Jackeline Martins $^{7}$
}

${ }^{1}$ Department of Speech Patology, Universidade Tuiuti do Paraná, Curitiba, PR, Brazil

${ }^{2}$ Cochlear Implant Ambulatory, Hospital Pequeno Príncipe, Curitiba, PR, Brazil

${ }^{3}$ Masters and doctorate in Communication Disorders program, Universidade Tuiuti do Paraná, Curitiba, PR, Brazil

4 Department of Phonoaudiology, Universidade Federal da Paraíba, Cidade Universitária, João Pessoa, PB, Brazil

${ }^{5}$ Department of Comunication Disorders, Universidade Tuiuti do

Paraná, Curitiba, PR, Brazil

6 Department of Phonoaudiology, Universidade Tuiuti do Paraná, Curitiba, PR, Brazil

${ }^{7}$ Department of Audiology, Audiotec, Curitiba, PR, Brazil

\author{
Address for correspondence Angela Ribas, PhD, Ambulatório de \\ Implante Coclear, Hospital Pequeno Príncipe, Rua Brigadeiro Franco \\ 2700, Curitiba, PR, 80250030, Brazil \\ (e-mail: fono.angelaribas@gmail.com).
}

Int Arch Otorhinolaryngol 2019;23:131-136.

\begin{abstract}
Keywords

- hearing

- language

- clinical protocols

- deafness

Introduction Cochlear implants are currently the most effective technological resource to facilitate access to the hearing world for deaf people. Their use, especially when implanted early in children, reduces the impact of deafness on hearing as well as on the development of spoken language.

Objective To validate the first part of the Brazilian Scale of Hearing and Language Development (EDAL-1, in the Portuguese acronym) and to establish the normal curve in infants and children aged between 0 and 24 months old with normal hearing.

Method This is an experimental study of a descriptive nature, conducted with 92 infants and children with normal hearing. Every infant/child was evaluated audiologically, and the EDAL-1 was applied to their parents. The responses were categorized by applying the EDAL-1 every 3 months for each child.

Results The EDAL- 1 was shown to be easily applied by the researcher and easily understood by the parents. It was possible to classify the sample every 3 months and describe the results. The average of the responses found in terms of scores for each age category shows an increasing scale following the evolution of the chronological age: 3 months -34.23 points; 6 months -54.68 points; 9 months -73 points; 12 months82.5 points; 15 months -87 points; 18 months -91 points; 21 months -92.5 points, and 24 months-95.83 points.

Conclusion The normal curve for EDAL-1 was successfully established. The averages can be considered as the standard protocol for normality, serving as a reference for comparison with other populations.
\end{abstract}

received

April 10, 2017

accepted

August 20, 2018

published online

February 15, 2019
DOI https://doi.org/

10.1055/s-0038-1675189. ISSN 1809-9777.
Copyright $(2019$ by Thieme Revinter

Publicações Ltda, Rio de Janeiro, Brazil
License terms

(ㄷ) (i) $\ominus$ (5) 


\section{Introduction}

The first years of life are considered critical for the development of the child. It is in childhood that the apex of the maturation process of the central auditory system occurs, as well as of the neuronal plasticity. ${ }^{1}$ In view of this, the early detection of hearing impairment is fundamental to minimize the losses and impacts caused by hearing loss in the development of language and of the hearing abilities of children. ${ }^{1-3}$

In this context, assessing the hearing of a young child requires health professionals to know the normal development of the child according to the corresponding age group. Currently, physicians and speech-language pathologists have at their disposal objective and subjective examinations, which, if properly applied, allow the efficient diagnosis of hearing loss in children at an early age, ${ }^{4}$ and when the auditory evaluation answers lead to the diagnosis of hearing loss, regardless of the degree of impairment, it is necessary to seek auditory rehabilitation through conventional or implantable prostheses. ${ }^{5}$

After adjusting the hearing device, it is essential to follow the evolution of the case, with frequent audiological adjustments and monitoring of speech acquisition and oral language. $^{3}$ The evaluation of these skills through standardized tests is important, since the documentation and the systematic analysis of the evolution of the child allow adequate orientation to the family and subsidizes the therapeutic conduct. ${ }^{6,7}$

Based on the National Health Policy for Persons with Disabilities implemented by the Ministry of Health throughout $\mathrm{Brazil}^{8}$ and on the advent of the compulsory newborn hearing screening, ${ }^{9}$ the number of deaf children who access hearing health services has increased, and the age of intervention has decreased, as recommended internationally, which is favorable to the development of hearing and oral language skills. ${ }^{3}$

In the hearing health services accredited by the Brazilian Public Health System (SUS, in the Portuguese acronym), the evaluation of hearing and language skills is essential and is foreseen in the general guidelines for the attention of the hearing impaired. ${ }^{10}$ Currently, the protocols used in the hearing health services in Brazil, such as meaningful use of speech scales (MUSS), infant-toddler meaningful auditory integration scale (IT-MAIS), Glendonald auditory screening protocol (GASP), meaningful auditory integration scale (MAIS), functioning after pediatric cochlear implantation (FAPCI), minimum hearing capacity evaluation test (TACAM, in the Portuguese acronym), Inventory Development Communication (IDC), and parents' evaluation of aural/oral performance of children (PEACH), are all international protocols translated into Portuguese. ${ }^{11}$ In places highly sought by patients, ${ }^{12}$ the use of many instruments could make it unfeasible to follow-up patients with hearing aids, both implantable and non-implantable.

In the hearing health service of the Hospital Infantil (Curitiba, state of Paraná, Brazil), the team of speech-language pathologists, after using the international instruments to register and provide information about the hearing and oral language development of the implanted patients, realized the need to elaborate a protocol to cover regional demands, that is, a protocol that is simple and quick to apply and easily understood by the parents/guardians. It was in this context that the Brazilian Scale for the Development of Hearing and Language (EDAL-1, in the Portuguese acronym) emerged, ${ }^{13}$ a rapid protocol composed of four tests, each one aimed at the evaluation of children in certain age groups.

The EDAL- $1,{ }^{14}$ the first battery test, which is the object of study in the present article, consists of 20 questions to be answered by the parents or guardians of deaf infants/children who have received cochlear implants at $<2$ years of hearing age, and is intended to evaluate the evolution of hearing and oral language skills after the prosthesis implantation.

The objective of the present study was to validate the EDAL-1 protocol ( - Table 1 ) and to establish the normality curve in normal hearing infants and children aged between 0 and 24 months old.

\section{Method}

This is an experimental, descriptive study, approved by the Research Ethics Committee under the number CEP/ 1.761.002. All of the participants signed the informed consent form, authorizing the use of the data collected.

A total of 92 children and their relatives (parents/guardians), randomly selected from the waiting room of the pediatric health service have participated, with 49 being male and 43 female. The study included children whose parents denied the presence of hearing loss. The data collection took place during the year of 2016 .

The parents were approached by the speech therapist/ researcher in the waiting room of the service and invited to evaluate the hearing of their children, and then to respond to a questionnaire. The study included infants and children aged between 0 and 24 months old at the time of the evaluation, who did not have hearing loss reported by the parents and/or no hearing loss observed in the auditory evaluation. Infants and children with otorhinolaryngological complaints, or with neurological and syndromic impairments capable of interfering with the auditory development, were excluded.

Data collection took place in two steps: Step 1-otoscopy, acoustic immittance, and behavioral observation audiometry (BOA). The audiological evaluation was performed in an acoustic booth. Step 2-application of the EDAL-1 on the parents of the child.

The otoscopy was considered normal when there was no alteration of the meatus and of the auditory canal capable of interfering in the auditory acuity of the child. The tympanometric curves, obtained through the Interacoustics AD-629 audiometer (Interacoustics, Middelfart, Denmark), were classified according to the Federal Council of Speech and Hearing Therapy (CFFa, in the Portuguese acronym) standards. ${ }^{15}$

The BOA is unreliable to determine auditory thresholds, but it has been performed to distinguish normality from alteration and to qualify the development of the auditory function, allowing, consequently, to verify the maturation of the central auditory nervous system. ${ }^{16}$ For the evaluation, a set of musical instruments that must have been evaluated beforehand in terms of frequency spectrum and intensity is required. We have used the following musical instruments: rattle (40dB); rattle (50dB); bell $(65 \mathrm{~dB})$; castanet $(75 \mathrm{~dB})$; cowbell $(85 \mathrm{~dB})$; 
Table 1 Brazilian Scale of Hearing and Language Development (EDAL-1, in the Portuguese acronym)

\begin{tabular}{|c|c|c|c|}
\hline Question & Behavior & Yes & No \\
\hline 1 & $\begin{array}{l}\text { a- Do you think your child listens? } \\
\text { b- Was the child's adaptation to the device positive? }\end{array}$ & & \\
\hline 2 & $\begin{array}{l}\text { a- Has your child ever had ear problems? Which were they? } \\
\text { b- Does your child use the device more than } 6 \text { hours a day? }\end{array}$ & & \\
\hline 3 & $\begin{array}{l}\text { a- Does he/she like to listen to music or TV? } \\
\text { b- Does he/she handle the hearing device? }\end{array}$ & & \\
\hline 4 & $\begin{array}{l}\text { a- Does he/she like noisy toys? } \\
\text { b- Does his/her behavior change when he/she is wearing the device? }\end{array}$ & & \\
\hline 5 & $\begin{array}{l}\text { a- Does he/she react to loud sounds? } \\
\text { b- Does he/she emit more vocalic sounds when he/she is wearing the device }\end{array}$ & & \\
\hline 6 & $\begin{array}{l}\text { a- Does he/she wake up with noises? } \\
\text { b- Does he/she get disturbed when the device does not work? }\end{array}$ & & \\
\hline 7 & Does he/she respond when called by name in a silent environment? & & \\
\hline 8 & Does he/she respond when called by name in a noisy environment? & & \\
\hline 9 & Does he/she respond to environmental sounds of everyday life? Which ones? & & \\
\hline 10 & Does he/she vocalize during communicative interactions? & & \\
\hline 11 & Does he/she use speech/vocalizations to attract the attention of others? Which ones? & & \\
\hline 12 & Do vocalizations vary according to the situation? & & \\
\hline 13 & Does he/she try to imitate sounds, words or vocalizations? Which ones? & & \\
\hline 14 & Does he/she move his/her body when he/she hears music? & & \\
\hline 15 & Does he/she identify different voices? & & \\
\hline 16 & Does he/she discriminate different sounds: voice, toys, music? & & \\
\hline 17 & Does he/she respond to simple questions without gesture support? & & \\
\hline 18 & Does he/she speak isolated words? Which ones? & & \\
\hline 19 & Is his/her vocabulary widening? & & \\
\hline 20 & Does he/she speak words in sequence? Which ones? & & \\
\hline
\end{tabular}

Source: Ribas A, Kochen AP. ${ }^{13}$

and snare drum $(100 \mathrm{~dB})$. The stimuli are presented in ascending order of intensity, for approximately three seconds, in the lateral plane to the ear in infants $\leq 9$ months old, and above the head for infants and children $>9$ months old, always within $20 \mathrm{~cm}$ from the ear. ${ }^{17}$ The behavioral auditory responses are qualitatively analyzed. The examiner completes the examination by calling the child by name and asking simple questions to check the reaction to the human voice.

The EDAL- 1 is a protocol consisting of 20 closed questions, which allow a quantitative analysis of the responses.

The instrument should be applied to the parents of the child being evaluated. Questions 1a, 2a, 3a, 4a, and 6a are intended for hearing children, and questions $1 \mathrm{~b}, 2 \mathrm{~b}, 3 \mathrm{~b}, 4 \mathrm{~b}$, $5 \mathrm{~b}$, and $6 \mathrm{~b}$ are intended for children with hearing aids. The answer to the question may be positive (worth 5 points), or negative (worth zero points), except for question 2a, which was reversed because its response being positive becomes a negative point in the evaluation. Each question with a yes answer is worth 5 points. At the end of the assessment, the number of positive responses is added, and it can range from zero to 100 . The higher the score, the better the child is developing.
According to Damourette et al, ${ }^{18}$ the development of hearing and language in infants and children from 0 to 24 months old occurs in a gradual and sequential way. Each step that is overcome serves as the basis for the next one. In this way, in terms of oral language, the child goes through periods of simple vocalizations, shouts, babbling, imitation of vowels followed by consonant sounds, speaking isolated words, and finally building expressions with a vocabulary of $\sim 20$ words. Regarding hearing, children pay attention to the sounds of the world, react to their name, take an interest in the sounds around them, know objects and people by name, and understand simple orders.

Thus, in addition to the quantitative analysis, the EDAL-1 allows a qualitative verification of the productions of the child, both regarding his/her auditory behavior and oral language, because the speech-language pathologist can record for each question how and what the child under evaluation produces from the point of view of the parents/guardians.

A longitudinal analysis of the results of the EDAL-1 can be performed to verify an increase of the score throughout the development of the child. In this way, the result obtained with the EDAL-1 can be compared with the subsequent 


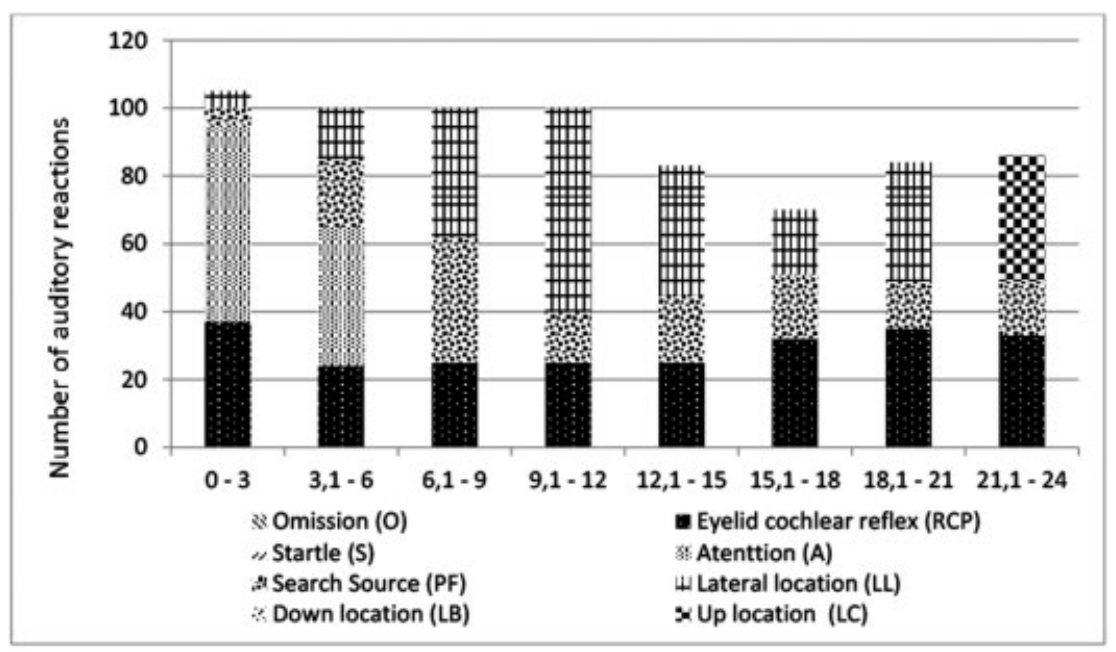

Fig. 1 Results observed in the behavioral observation audiometry $(N=92)$.

results of the children in order to trace an evolutionary line of their hearing performance and oral language, or it can be compared with the results of other children, seeking to determine deviations from normality. Like many questionnaires answered by parents/guardians, the main limitation is that they are indirect measurement instruments based on the responses of an observer.

In the present study, the results obtained in the EDAL-1 were treated qualitatively and compared with auditory behavioral responses to determine their normality pattern.

\section{Results}

The 92 infants/children who composed the sample were categorized according to age, considering age groups of three months. Boys and girls were included in all age groups. The total was 49 boys and 43 girls. All of the infants/children had normal otoscopy results and type A tympanometric curves.

The results are shown in - Fig. 1, where it is possible to verify that as the child grows, the more consistent are the responses to the sound.
The voice responses are shown in $\mathbf{- F i g . ~ 2 , ~ w h e r e ~ i t ~ i s ~ a l s o ~}$ possible to verify that the auditory response improves as the child grows.

- Table 2 shows the results obtained with the EDAL-1. The average answers found for each period of 3 months of age shows an increasing scale accompanying the chronological evolution of the child. The maximum point of positive responses in the protocol is found when the chronological age reaches 24 months.

-Fig. 3 demonstrates the normality curve for the EDAL-1, considering the results obtained in each age group. The standard deviation observed in each age group is shown in -Table 2 and complements the graph.

\section{Discussion}

The present study discusses the development of a hearing and language scale for evaluation in a speech therapy ambulatory for the follow-up of cochlear implanted infants/children. To do so, it took into account a behavioral-based hearing test ${ }^{17}$ that allowed the determination of the hearing

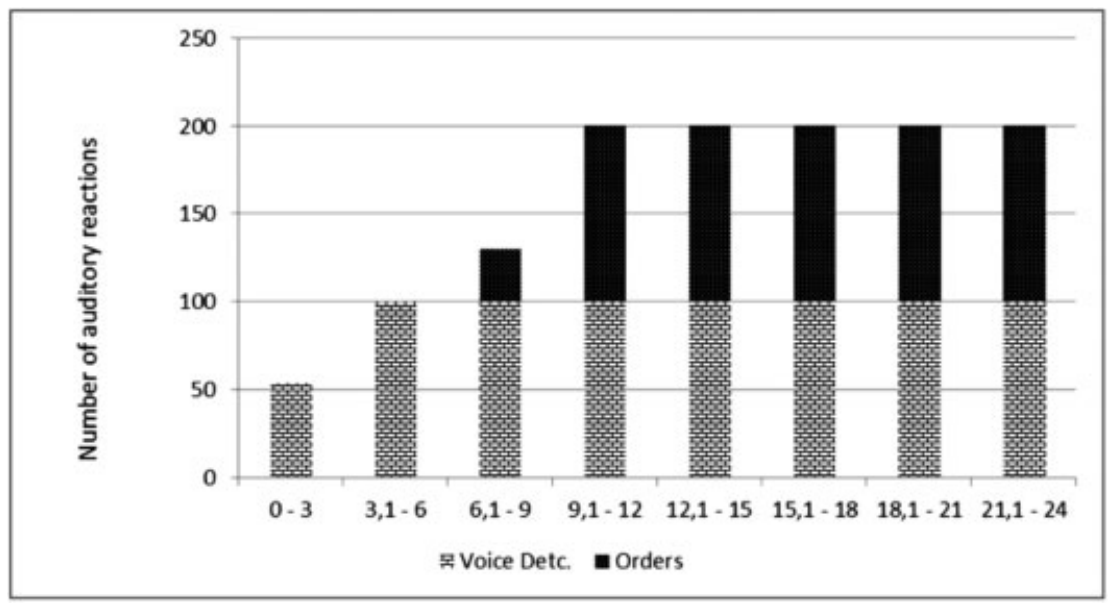

Fig. 2 Test result for verbal sounds $(N=92)$. 
Table 2 Results of the Brazilian Scale of Hearing and Language Development (EDAL -1 , in the Portuguese acronym) $(N=92)$

\begin{tabular}{|l|l|l|l|l|l|l|}
\hline Months & Number & Minimum & Maximum & Average & SD & Mean \\
\hline $0-3$ & 13 & 25 & 50 & 34.23 & 8.12 & 30 \\
\hline $3.1-6$ & 16 & 40 & 70 & 54.68 & 8.65 & 55 \\
\hline $6.1-9$ & 10 & 60 & 85 & 73.0 & 10.59 & 75 \\
\hline $9.1-12$ & 10 & 65 & 100 & 82.50 & 10.34 & 80 \\
\hline $12.1-15$ & 10 & 75 & 100 & 87.0 & 7.52 & 85 \\
\hline $15.1-18$ & 10 & 85 & 100 & 91.0 & 5.16 & 90 \\
\hline $18.1-21$ & 10 & 80 & 100 & 92.50 & 6.34 & 95 \\
\hline $21.1-24$ & 13 & 85 & 100 & 95.83 & 5.06 & 95 \\
\hline
\end{tabular}

Abbreviation: SD, standard deviation.

level of the infants/children assessed, both quantitatively and qualitatively, as well as a standard language development scale ${ }^{18}$ recognized in the literature.

The EDAL instrument was developed to be applied to the parents or guardians of the child, considering the age range for which it is intended. Although observation of behavior in ludic situations gives better subsidies to the examiner, tests based on answers by the parents are routinely used, ${ }^{19}$ since they do not require the cooperation of the child and less time is spent, which is consistent with the reality of the SUS ambulatories. Studies ${ }^{1}$ show that the sooner the diagnosis of deafness is made, the better the results of intervention and rehabilitation, so that the development of the deaf child can be closer to the hearing peers and evaluating these responses in infants/children under 24 months old can be an arduous task, especially in cases of deafness. ${ }^{19}$

According to - Fig. 1, all of the infants/children who participated in the present study presented positive answers for the auditory evaluation, confirming the information that the group studied was of normal hearing infants/children. A study conducted with Brazilian children ${ }^{17}$ concluded that the auditory abilities progress with the passage of time, from birth until 12 months old, when the infant can locate the sound source in all directions. This period is known as prelinguistic and corresponds to the first year of life and it is when the baby establishes the basis of communication with those around him. It can be said that, at this stage, the child

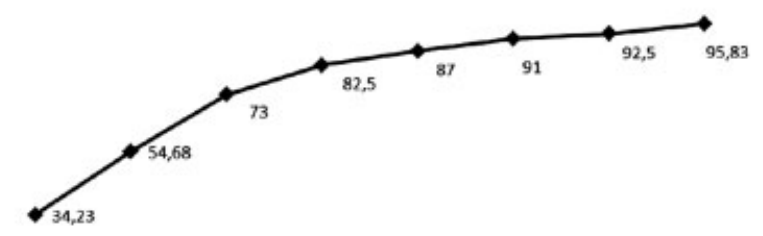

$\begin{array}{llllllll}0.3 & 3,1-6 & 6,1-9 & 9,1-12 & 12,1-15 & 15,1-18 & 18,1-21 & 21,1-24\end{array}$

Fig. 3 Normality curve of the Brazilian Scale of Hearing and Language Development (EDAL-1, in the Portuguese acronym). learns to listen, and the perception of speech sounds is the first step in understanding oral language ${ }^{20}$.

The normal development of the child still intrigues and impresses speech therapists and other professionals who study language and hearing, for its beauty and complexity. Although several studies ${ }^{11}$ describe how this process occurs, in some cases the creation of instruments with differentiated criteria becomes necessary. This is the case of hearing health services, where the indication and adaptation of hearing aids for deaf children occurs. These services are highly sought by patients, ${ }^{12}$ and there is a preference for fast protocols that verify the evolution of the patient without, however, compromising the agenda that is, in general, extensive. ${ }^{19}$ In this sense, in response to this need, EDAL-1 was developed, which has an average application time of 4.28 minutes, ranging from 2.30 to 11.30 minutes. $^{13}$

Although it is an indirect measurement instrument that is based on the responses of an observer, when the bidirectional interaction between parents and children is considered, it is necessary to realize that communication is dependent on this interaction. ${ }^{11}$ Therefore, based on this assumption, it was possible to establish the normality curve of the EDAL- 1 for every 3 months of age, between 0 and 2 years old, as shown in - Fig. 3.

According to the results, it was verified that the score increases as the age increases. Other more complex protocols, ${ }^{11,21,22}$ which also make cross-sections, verified the same phenomenon, indicating that increasing age promotes maturation of behavior.

Hearing is a natural human process upon which learning is built. ${ }^{23}$ In this way, the development of oral language skills is imbued with auditory learning, which means, insofar as the children learn to listen, they build the linguistic framework and learn to speak. ${ }^{24}$ This process could be verified in the present study, especially when comparing the results of -Figs. 1 and 2. In - Fig. 1, it is possible to visualize the increase in the number and complexity of behavioral responses to the sound stimuli as the chronological age of the child progresses. Infants aged between 0 and 3 months old only react reflexively and instinctively to sound. ${ }^{17}$ More mature children learn to locate the sound source in several directions. The same reasoning applies to - Fig. $\mathbf{2}$, where it is possible to verify that very 
small children react with attention to the voice and then, as they grow, respond to simple orders.

Finally, since the EDAL- $1^{13,14}$ is intended for the rapid evaluation of infants and children who have received cochlear implants between 0 and 2 years old, it is important to emphasize that the comparison of the child evaluated with the gold standard will not always be equivalent due to the multivariate factors that interfere with the rehabilitation of the deaf child. ${ }^{25}$ The objective of the group of professionals of the public service where the protocol EDAL-1 was developed was fulfilled. It has also been shown that, characterizing the evolution of a particular child, it is possible to compare the results with a group (here proposed as the gold standard of the test), or with his own results, considering the previous results of the child.

Although the respondents stated that the language used in the protocol is clear, a limitation of the present study was not having verified the internal consistency of the protocol by a statistical index, as the literature advocated. ${ }^{11}$ For this, it would be necessary to apply the same protocol twice, to the same respondents, in a determined interval of time, which was not performed in the present research.

\section{Conclusion}

The normality curve for the EDAL-1 was successfully established. The averages obtained can be considered as the standard of normality for the test, serving as a reference for comparison with other populations.

\section{References}

1 Yoshinaga-Itano C. From Screening to Early Identification and Intervention: Discovering Predictors to Successful Outcomes for Children With Significant Hearing Loss. J Deaf Stud Deaf Educ 2003;8(01):11-30

2 Silva AB, Pereira MC, Zanolli ML. Deafness: from suspicion to referral for intervention. Rev Paul Pediatr 2012;30:257-262

3 Bevilacqua MC, Moret ALM, Costa OA. Conceituação e indicação do implante coclear. In: Bevilacqua MC e org. Tratado de Audiologia. 1a ed. ( ${ }^{\circ}$ reimp.). São Paulo: Santos; 2013

4 Maia APJS. Avaliação auditiva: como proceder. Revista de Pediatria SOPERJ. 2011(suplemento):35-39

5 Iório MCM. Avaliação de resultados - Estudos de qualidade de vida. In: Bevilacqua MC, Martinez MAN, Balen SA, Reis ACMB, Frota S. Tratado de Audiologia. 1a ed. São Paulo: Santos; 2013

6 Mylanus E, Vermeulen A, Neijenhuis K, Snik A. Auditory and language assessment tools in pediatric cochlear implant patients: a follow-up study. In: Abstracts of the 8 European Symposium Pediatric Cochlear Implants; 2006 Mar 25-28; Palazzo del Cinema. Lido di Venezia; 2006. p.106.

7 Donaldson GS, Dawson PK, Borden LZ. Within-subjects comparison of the HiRes and Fidelity120 speech processing strategies: speech perception and its relation to place-pitch sensitivity. Ear Hear 2011;32(02):238-250

8 BRASIL. Política Nacional de Saúde da Pessoa com Deficiência. Brasília: Ministério da Saúde: Brasília; 2010

9 BRASIL. Diretrizes de Atenção da Triagem Auditiva Neonatal. Brasília: Ministério da Saúde: Brasília; 2013

10 BRASIL. Diretrizes Gerais para Atenção Especializada às Pessoas com Deficiência Auditiva no Sistema Único de Saúde (SUS). Ministério da Saúde: Brasília; 2014

11 Vassoler TM, Cordeiro ML. Brazilian adaptation of the Functioning after Pediatric Cochlear Implantation (FAPCI): comparison between normal hearing and cochlear implanted children. J Pediatr (Rio J) 2015;91(02):160-167

12 Ribas A, Serratto MR, Bento K, Vieira M, Lourenço H, Costa T. Perfil sociohistórico de pacientes atendidos na clínica de fonoaudiologia da Universidade Tuiuti do Paraná. Rev. Biociências. Tecnologia e Saúde. 2012;5:13-22

13 Ribas A, Kochen AP. Échelle bresiliennede development de l'audition et du langage (EDAL) chez les enfants de moins de deux ans porteurs d'implants cochleaires. In: 12 European Symposiun on Pediatric Cochlear Implants, 2015, Toulouse. 12th ESPCI, 2015

14 Ribas A, Kochen AP. Brazilian scale of hearing and language development in children (EDAL-1) with cochlear implant and less than two years of hearing AGE. Int Tinnitus J 2016;20(01):7-10

15 CFFA. Manual de Procedimentos em Audiometria Tonal Limiar, Logoaudiometria e Medidas de Imitância Acústica. Conselho Federal de Fonoaudiologia: Brasília; 2013

16 Northen JL, Downs MP. Avaliação auditiva comportamental. In: Northen L, Downs MP (eds). Audição na infância. 5a ed. Rio de Janeiro: Guanabara Koogan; 2002:359

17 Azevedo MF, Vieira RM, Vilanova LCP. Desenvolvimento auditivo de crianças normais e de alto risco. São Paulo: Plexus; 1995

18 Damourette J, Pichon E. Des mots à la pensée:essai de grammaire de la langue française. Paris: Editions d'Atrey; 1943

19 Pinto ESM, Lacerda CBF, Porto PRC. Comparação entre os questionários IT-MAIS e MUSS com vídeo-gravação para avaliação de crianças candidatas ao implante coclear. Rev Bras Otorrinolaringol 2008;74(01):91-98

20 Pedroso FS, Rotta NT, Danesi MC, Avila LN, Savio CB. Evolution of pre-linguistc manifestations in normal infants during the first year of life. Rev Soc Bras Fonoaudiol 2009;14:22-25

21 Ribas A, Zeigelboim BS, Massi GA. Comparando resultados de aplicações do QI-AASI em idosos protetizados. Geriatria \& Gerontologia. 2013;7:54-59

22 Clark JH, Aggarwal P, Wang NY, Robinson R, Niparko JK, Lin FR. Measuring communicative performance with the FAPCI instrument: preliminary results from normal hearing and cochlear implanted children. Int J Pediatr Otorhinolaryngol 2011;75(04): 549-553

23 Vygotski L. Fundamentos da defectologia. Cuba: Pueblo e Educación; 1995

24 Ribas A. A relação entre o processamento auditivo central e o distúrbio de aprendizagem. [dissertation]. CuritibaUniversidade Tuiuti do Paraná, Programa Distúrbios da Comunicação1999:112

25 Stuchi RF, Nascimento LT, Bevilacqua MC, Brito Neto RV. [Oral language of children with five years of experience using [corrected] cochlear implant]. Pro Fono 2007;19(02):167-176 